\title{
Cholelithiasis in a Filipino Child with Chronic Neuronopathic Gaucher Disease: A Case Report
}

\author{
Mary Ann R. Abacan ${ }^{1}$ and Mary Anne D. Chiong ${ }^{1,2}$ \\ ${ }^{1}$ Institute of Human Genetics, National Institutes of Health, University of the Philippines Manila \\ ${ }^{2}$ Section of Genetics, Department of Pediatrics, College of Medicine and Philippine General Hospital, University of the Philippines Manila
}

\begin{abstract}
Gaucher disease is the most common of the lysosomal storage diseases caused by a defect in the lysosomal enzyme $\beta$ glucocererbrosidase resulting in multi-organ involvement. The presence of cholelithiasis has been rarely observed among patients with non-neuronopathic type of Gaucher disease and the exact pathophysiology is still unknown. We report a Filipino child with chronic neuronopathic Gaucher Disease noted to have cholelithiasis on routine whole abdominal ultrasonography as part of the regular monitoring of the disease.
\end{abstract}

Key Words: Gaucher disease, neuronopathic Gaucher, cholelithiasis, type 3 Gaucher disease

\section{Introduction}

Gaucher disease, the most prevalent sphingolipid storage disorder, is caused by a deficiency in the activity of the lysosomal enzyme $\beta$-glucocerebrosidase and results in multi-organ involvement because of accumulation of glycolipid in cells of the monocyte-macrophage system. ${ }^{1}$ The birth frequency of Gaucher disease is 1:60,000 live births in the general population. ${ }^{2}$ In the Philippines, there are eleven patients listed in the registry of the National Institutes of Health.

This condition has been classified into three types. The non-neuronopathic is associated with subtotal deficiency of the enzyme ${ }^{2}$ and constitutes $80-90 \%$ of cases. ${ }^{3}$ Manifestations are in the viscera, principally the liver and spleen, as well as bone marrow and skeletal system ${ }^{2}$ but $25 \%$ of affected individuals may be asymptomatic or have splenomegaly discovered incidental to an examination well into adult life. ${ }^{4}$ The acute neuronopathic form, is characterized by neurological impairment in addition to visceral symptoms. ${ }^{5}$ Less than $10 \%$ of patients with Gaucher disease develop a chronic neuronopathic form with visual gaze palsies and other manifestations including myoclonic epilepsy and

\footnotetext{
Corresponding author: Mary Ann R. Abacan, MD

Institute of Human Genetics

National Institutes of Health

University of the Philippines Manila

623 Pedro Gil St., Ermita, Manila 1000 Philippines

Telephone: +6325367002

Email: mrabacan@up.edu.ph
}

nerve deafness - all of which may be complicated by variable systemic involvement. ${ }^{2}$

Cholelithiasis has been observed among patients with non-neuronopathic Gaucher disease with variable frequency. ${ }^{1}$ The abnormal metabolism of glycolipids and plasma lipoproteins may contribute to cholesterol gallstones in Gaucher disease. ${ }^{6}$

We report a 12-year-old Filipino child diagnosed with chronic neuronopathic Gaucher disease noted to have cholelithiasis.

\section{Case Report}

Our patient is a 12-year-old female who underwent screening for Gaucher disease at 4 years and 6 months of age, a year after her twin sister was diagnosed with the same disorder. At the time of the diagnosis, she had hepatosplenomegaly (liver edge palpable $4.5 \mathrm{~cm}$ below the right costal margin and splenic edge palpable $5 \mathrm{~cm}$ below the left coastal margin) and episodes of bleeding (petechiae at the mandibular area, bruising and epistaxis). A bone marrow aspiration biopsy done showed presence of Gaucher cells. The diagnosis was confirmed through enzyme analysis which showed a low b-glucocerebrosidase activity of $0.88 \mathrm{nmol} / \mathrm{mg} \mathrm{prot} / \mathrm{hr}(\mathrm{NV}=>5.10 \mathrm{nmol} / \mathrm{mg} \mathrm{prot} / \mathrm{hr})$ and DNA mutation analysis which revealed the L444P and P319A (c 1072 C-G, exon 8) mutations.

She is the younger of twins in a sibship of four, born to a healthy non-consanguineous couple of Filipino descent. There is a family history of rheumatic heart disease in her mother, asthma in a maternal uncle and hypertension in a maternal grandfather. Her twin sister was diagnosed with Gaucher disease at 3 years of age initially presenting with a gradual abdominal enlargement and epistaxis, and eventually developed seizures at 9 years of age.

She has been receiving enzyme replacement therapy with imiglucerase (Cerezyme) every two weeks at a dose of $60 \mathrm{IU} / \mathrm{kg}$ since she was 5 years of age. Improvement has been noted through the decrease in size of her visceral organs and resolution of anemia and thrombocytopenia. She has mild mental retardation. On the basis of her clinical presentation and mutations, she was diagnosed to have chronic neuronopathic Gaucher disease.

As part of monitoring of her condition, an annual ultrasound of the whole abdomen done showed the 
following results: slightly enlarged liver $(12.9 \mathrm{~cm})$ with smooth borders; intrahepatic ducts and common bile duct $(1.8 \mathrm{~mm})$ are not dilated; the gallbladder is well distended with unthickened walls; multiple high intensity echoes with posterior sonic shadowing with aggregate diameter of $1.3 \mathrm{~cm}$ are seen intraluminally. The assessment was mild hepatomegaly with cholelithiasis.

At the time of the finding, our patient did not have any subjective complaints and had undergone 102 enzyme infusions. Her weight was $31.5 \mathrm{~kg}$ (between $3^{\text {rd }}$ and $10^{\text {th }}$ percentiles), height was $136 \mathrm{~cm}$ ( $3^{\text {rd }}$ percentile) and BMI was $17 \mathrm{~kg} / \mathrm{m}^{2}$ (between $25^{\text {th }}$ and $50^{\text {th }}$ percentiles). Further work-up as to the origin of the lithiasis was done. Plasma uric acid 0.2 $\mathrm{mmol} / \mathrm{L}$ (NV=0.11-0.43), HDL $1.02 \mathrm{mmol} / \mathrm{L}$ (NV=0.91-1.56), LDL mmol/L $2.6(\mathrm{NV}=1.10-3.8)$ and cholesterol $4.7 \mathrm{mmol} / \mathrm{L}$ $(\mathrm{NV}=4.2-5.2)$ were within normal limits. Plasma triglyceride was elevated at $2.28 \mathrm{mmol} / \mathrm{L}(\mathrm{NV}=0.34-1.70)$. $\mathrm{CBC}$ and liver function tests were normal.

She underwent removal of gallstones through laparoscopic surgery two months after it was noted on ultrasound. However, no stone analysis was done. She has completely recovered from the surgery and repeat ultrasound of the whole abdomen done six months after surgery showed absence of the gallbladder stones but still with slight hepatomegaly.

At present, she is still undergoing regular enzyme replacement therapy every two weeks with Cerezyme at a dose of $60 \mathrm{IU} / \mathrm{kg}$.

\section{Discussion}

Studies in pediatric patients estimate an overall prevalence of $0.13 \%$ to $1.9 \%$ for gallstone disease in children up to 19 years of age. ${ }^{7}$ The risk factors for cholelithiasis are age, female sex, fertility, excess weight, rapid weight loss, hypertriglyceridemia, genetic predisposition such as Gilbert syndrome, various drugs and hormones, terminal ileal resection and gallbladder hypomotility. ${ }^{1}$ More than $70 \%$ of gallstones in children are the pigment type, $15-20 \%$ are cholesterol stones, and the remainder are composed of a mixture of cholesterol, organic matrix and calcium bilirubinate. ${ }^{8}$

The high incidence of gallstones in patients with Gaucher disease has been attributed to the high frequency of routine abdominal imaging, which would increase the likelihood that gallstones would be found.9,10 However, patients with Gaucher disease do have several risk factors associated with the development of gallstones which is a common feature associated with other inherited anemias which include an older age group, a family history of cholelithiasis, higher BMI values, higher LDL levels, increased disease severity and previous splenectomy; in addition, advanced liver disease and cirrhosis which are sometimes seen in patients with Gaucher disease also predispose to gallstones. ${ }^{10}$ The decreased hepatic secretion of bile salts and phospholipids due to the impaired hepatic synthesis causes the bile to be lithogenic.9,10

Taddei et al. ${ }^{6}$, found an unexpectedly high prevalence of cholesterol gallstones among patients with nonneuronopathic Gaucher disease with the general perception that gallstones in non-neuronopathic Gaucher disease represent pigment stones associated with apparently shortened red blood cell survival in this disorder. Further, they report that the propensity for forming gallstones is associated with abnormal lipid profiles where both LDL and HDL levels are extremely low but triglyceride levels remain normal. Our patient's lipid profile revealed a high triglyceride level but normal LDL and HDL. Unfortunately, stone analysis was not done in our patient and the etiology of the stone could not be ascertained.

Despite numerous studies, the metabolic factors associated with gallstones in non-neuronopathic Gaucher disease are not known, nor is the chemical composition of stones or bile. ${ }^{6}$ Thus, the pathophysiology of cholelithiasis in Gaucher disease remains unknown. ${ }^{6,10}$

Being made aware that patients with Gaucher disease are at increased risk for developing gallstones, continuous monitoring of lipid profile and routine whole abdominal ultrasonography should be done for early detection and management. Likewise, prevention and avoidance of risk factors for cholelithiasis should similarly be encouraged among children and adults with Gaucher disease.

\section{Statement of Authorship}

All authors have approved the final version of the manuscript.

\section{Author Disclosure}

All authors have declared no conflicts of interest.

\section{Funding Source}

This paper was self-funded.

\section{References}

1. Ben Harosh-Katz M, Patlas M, Hadas-Halpern I, Zimran A, Elstein D. Increased prevalence of cholelithiasis in Gaucher Disease: association with splenectomy but not with Gilbert syndrome. J Clin Gastroenterol. 2004; 38(7):586-9.

2. Cox TM. Gacuher disease: clinical profile and therapeutic developments. Biologics: Targets and Therapy 2010; 4:299-313.

3. Vanier MT. Disorders of Sphingolipid Metabolism. In: Fernandes J, Saudubray JM, van den Berghe G, Walter JH. Inborn Metabolic Diseases, $4^{\text {th }}$ ed. Pringer Medizin Verlag; 2006. pp.481-482.

4. Nyhan WL, Barshop BA, Ozand P. Atlas of Metabolic Diseases, $2^{\text {nd }}$ ed. Great Britain: Oxford University Press; 2005. pp. 626-634.

5. Jmoudiak M, Futerman AH. Gaucher disease: pathological mechanisms and modern management. Br J Haematol. 2005; 129(2):178-88. 
6. Taddei TH, Dziura J, Chen S, et al., High incidence of cholesterol gallstone disease in type 1 Gaucher disease: characterizing the biliary phenotype of type 1 Gaucher disease. J Inherit Metab Dis. 2010; 33(3):291-300.

7. Herzog D, Bouchard G. High rate of complicated idiopathic gallstone disease in pediatric patients of a North American tertiary care center. World J Gastroenterol. 2008; 14(10):1544-8.
8. Migita M, Kumasaka S, Matsumoto T, Tijima H, Ueda T, Yamataka A Cholelithiasis in a patient with Type 2 Gaucher Disease. J Nippon Med Sch. 2014; 81(1):40-2.

9. Avdaj A, Fanaj N, Osmani M, Bytyqi A, Cake A. Case report of cholelithiasis in a patient with type 1 Gaucher Disease. Int J Surg Case Rep. 2016; 29:227-9.

10. Rosenabum H, Sidransky E. Cholelithiasis in patients with Gacuher disease. Blood Cells Mol Dis. 2002; 28(1):21-7.

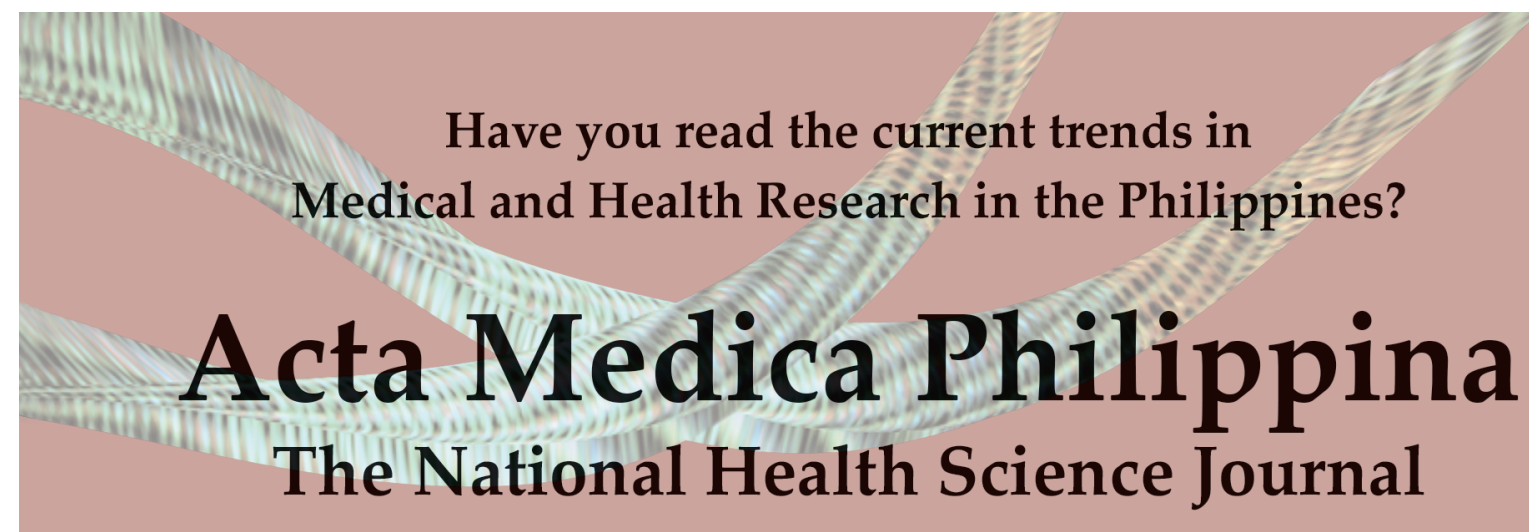

Now available for free at the Apple app store and Google play store.
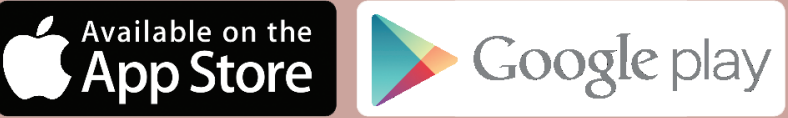